\title{
A retrospective observational study on the treatment outcomes of 26 patients with spinal cord astrocytoma including two cases of malignant transformation
}

\author{
Seong Jun Ryu ${ }^{1} \cdot$ Jong Yul Kim ${ }^{1} \cdot K_{\text {Kung Hyun Kim }}^{1} \cdot$ Jeong Yoon Park ${ }^{1}$. \\ Sung Uk Kuh ${ }^{1}$ - Dong Kyu Chin ${ }^{1}$ Keun Su Kim ${ }^{1}$ - Yong Eun Cho ${ }^{1}$. \\ Se Hoon Kim ${ }^{2}$
}

Received: 30 October 2015/Revised: 22 February 2016/ Accepted: 23 February 2016/Published online: 16 March 2016

(C) The Author(s) 2016. This article is published with open access at Springerlink.com

\begin{abstract}
Purpose To determine the biologic behavior and prognostic factors of spinal cord astrocytoma, we reviewed surgical and clinical outcomes. Due to the rarity of spinal cord astrocytoma, there is a lack of research regarding this type of tumor and malignant transformation.

Methods We retrospectively reviewed the data from all patients on whom we performed spinal cord tumor removal between 1983 and 2014. Twenty-six patients were pathologically confirmed to have spinal cord astrocytoma or glioblastoma. Surgical extent and disease progression were confirmed by the surgeon based on operative findings, postoperative MRI, and outpatient department (OPD) follow-up. Results Pain or neurological deficit was the chief complaint for all patients. With MRI studies, there is a tendency for highgrade astrocytomas to show as enhanced and heterogeneous images. Two of the low-grade astrocytomas showed malignant transformation over the course of 4 and 11 months, respectively. The overall survival (OS) for low-grade astrocytoma was 28-480 months (mean 156.38 months); the OS for highgrade astrocytoma was 1-36 months (mean 12.00 months). Conclusions Two of 12 low-grade cases showed malignant transformations at 4 and 11 months, respectively,
\end{abstract}

Yong Eun Cho

yecho@yuhs.ac

$\triangle$ Se Hoon Kim

PAXCO@yuhs.ac

1 Department of Neurosurgery, Gangnam Severance Hospital, The Spine and Spinal Cord Institute, Yonsei University College of Medicine, 211, Eonju-ro Gangnam-gu, Seoul 135-720, South Korea

2 Department of Pathology, Severance Hospital, Yonsei University College of Medicine, Seoul, Korea based on pathological confirmation. With spinal cord astrocytomas, enhanced MRI results appeared similar to those of a malignant lesion. We suggest close observation and image correlation of low-grade astrocytomas, even when pathologically confirmed as low-grade. In this review, we found that histologic grade is the most important prognostic factor, although it is not always concordant with biologic behaviors.

Keywords Spinal cord neoplasm - Astrocytoma . Malignant glioma - Radiotherapy · Survival

\section{Introduction}

Spinal cord tumors comprise only $2-4 \%$ of CNS neoplasms in adults, one-third of which are located intramedullary [1-4]. Intramedullary spinal cord astrocytomas account for 6-8 \% of all primary spinal cord tumors [5-7], indicating their rarity. Few investigations into the pathologic features, postoperative outcomes, surgical experience, or chemotherapy regimens have been published for these tumors; [1, 8-10] therefore, information is lacking on the common clinico-radio-pathologic features of spinal cord astrocytomas. Low-grade histologic findings, which include pilocytic astrocytomas, diffuse astrocytomas, and pilomyxoid astrocytomas, are more common than highgrade findings, such as anaplastic astrocytomas (AA) and glioblastoma (GB) [4, 11, 12].

For treating low-grade primary spinal cord gliomas, gross total resection is considered the gold standard when possible and has an excellent local control rate. Additional radiation therapy is recommended for cases of partial resection. There is currently no gold standard treatment for malignant primary spinal cord glioma [10]. 
MRI plays an important role in predicting tumor type before confirmation through histologic diagnosis, helping to establish an appropriate treatment plan. MRI, particularly contrast-enhanced imaging, not only shows the exact locations and extensions of intramedullary tumors but also differentiates between tumor cysts and tumor-related benign fluid collection [13]. Specifically, astrocytomas tend to have slightly fewer well-defined margins and are more likely to be eccentrically located within the spinal cord. Lesions on the spinal cord appear as isointense or hypointense when viewed on Tl-weighted imaging and as hyperintense on T2-weighted imaging; these lesions can be enhanced with contrast despite their low histological grade [11]. It is important to differentiate between benign and malignant tumors before establishing a treatment plan for spinal cord astrocytomas. Unfortunately, there are only a sparse number of reports on radiologic differentiation between benign and malignant spinal cord astrocytoma.

To investigate the radiologic findings, prognostic factors, pathologic features, postoperative outcome, and natural behavior patterns that are common with spinal cord astrocytomas, we retrospectively reviewed 26 cases of surgically verified spinal cord astrocytomas in patients who visited our institute. We identified several astrocytomaspecific associations with clinical behavior, MRI features, and pathology. Our findings will be helpful in distinguishing between malignant and benign spinal cord astrocytomas, predicting prognosis, and performing an early selection of the best treatment option and strategy.

\section{Materials and methods}

\section{Patient selection}

We retrospectively reviewed the medical records of 26 patients who were diagnosed with and surgically treated for pathologically verified spinal cord astrocytoma at our hospital from 1983 to 2014. Two patients experienced malignant transformation; thus, our review included a pathologic description of malignant transformation into glioma. The study was approved by the Institutional Review Board at the Human Research Protection Center of our hospital.

\section{Patient evaluation and data collection}

Medical records were reviewed for age, sex, symptom presentation, primary complaint, duration of chief complaint prior to diagnosis, and preoperative and postoperative neurological function status. Functional status was retrospectively evaluated using the Nurick score (Table 1) [14].
Table 1 Nurick score for assessment of neurological function

\begin{tabular}{ll}
\hline Grade & Description \\
\hline 0 & $\begin{array}{c}\text { Signs or symptoms of root involvement but without evidence } \\
\text { of spinal cord disease }\end{array}$ \\
1 & $\begin{array}{l}\text { Signs of spinal cord disease but no difficulty in walking } \\
2\end{array}$ \\
$\begin{array}{l}\text { Slight difficulty in walking that did not prevent full-time } \\
\text { employment }\end{array}$ \\
$\begin{array}{l}\text { Difficulty in walking that prevented full-time employment or } \\
\text { the ability to perform all housework but that was not severe } \\
\text { enough to require someone else's help to walk }\end{array}$ \\
4 & $\begin{array}{l}\text { Able to walk with someone else's help or the aid of a frame } \\
\text { Chair-bound or bedridden }\end{array}$ \\
\hline
\end{tabular}

Tumor extension, location, and pathologic grade were obtained from each patient's radiological and pathological records. Postoperative patients were followed-up with enhanced-material MRI. Surgical extent and disease progression were confirmed on postoperative and follow-up MRI. Microscopic preparations were reviewed, and tumors were classified according to current $\mathrm{WHO}$ criteria as grade I, II, III, or IV. One experienced neuropathologist confirmed the astrocytoma type from the slides for all cases in this study; astrocytomas were classified as pilocytic astrocytoma, diffuse astrocytoma, anaplastic astrocytoma, or glioblastoma.

\section{Surgical procedures}

All surgeries were performed with the patient in prone position on the operating table. From 2010, somatosensoryevoked potentials and motor-evoked potentials were monitored and updated through out the operations. The suspected tumor location region, as determined by MRI, was marked with an $18 \mathrm{G}$ needle and a portable X-ray image, and a laminectomy was performed over the region. A dura incision and midline myelotomy were performed using an intraoperative microscope. The operator decided the extent of resection, relying on the tumor cleavage plane in the operation field, and, from 2010, MEP changes were also considered. Gross total tumor removal or subtotal tumor removal was performed, with the exception of one patient who underwent several diagnostic biopsies. For all patients, a dura suture with meticulous attention toward hemostasis was performed. A hemovac was inserted, and the wound was closed layer-by-layer. All patients tolerated the operation well.

\section{Adjuvant treatment}

Nine of 14 patients who had a pathologically confirmed high-grade astrocytoma received radiotherapy. One patient diagnosed with a low-grade astrocytoma also received 
radiotherapy. Three patients underwent chemotherapy following their operation. Either temozolomide and vincristine plus carboplatin or temozolomide alone were used as chemotherapy agents.

\section{Statistical methods}

To analyze the relationships between behavior patterns and tumor-grade characteristics (low-grade $=$ WHO grades $\mathrm{I}$ and II; high-grade $=$ WHO grades III and IV), we performed Mann-Whitney tests using the following variables: age, sex, preoperative neurological status, postoperative neurological status, duration of chief symptom complaint until diagnosis, tumor location, tumor size, extent of resection, and MRI findings. Additionally, Ki-67 index and postoperative radiotherapy prognosis were analyzed. Categorical and grouped continuous variables with more than four categories were aggregated according to clinical significance or median value; these included patient age $(\geq 40$ vs. $<40$ ), sex, tumor location (cervical/cervicothoracic vs. thoracic/thoracolumbar), Ki-67 index ( $\geq 5$ vs. $<5 \%$ ), and surgical extent (total resection or gross total resection vs. subtotal resection or partial resection).

Overall survival (OS) and progression-free survival (PFS) were estimated using a Kaplan-Meier curve, and the log-rank test was used to compare the survival distributions. OS was defined as the duration from the date of diagnosis to the date of final follow-up or death. PFS was defined as the duration from the date of diagnosis to the date of tumor progression or death. A Cox proportional hazards model was used to determine significant risk factors for death. For these models, we first performed univariate analyses on all potential independent variables. Next, we performed multivariate analyses using only the variables that were significant in our univariate models.

All statistical tests were two-sided, and statistical significance was defined as a $p$ value of $\leq 0.05$. All statistical tests were conducted using SPSS, version 20.0, (Armonk, NY, USA).

\section{Results}

Twenty-six patients (17 men, 9 women; mean age 38.9 years; range 14-76 years) were enrolled in this study. Tumor locations included the cervical region $(n=11$ cases), the thoracic region ( $n=8$ cases), the thoracolumbar region ( $n=5$ cases), and the cervicothoracic region ( $n=2$ cases). The histologic grades of the tumors were high-grade astrocytoma ( $n=14$ cases), which included anaplastic astrocytoma and glioblastoma as well as two patients who experienced malignant transformation from diffuse astrocytoma to anaplastic astrocytoma, and lowgrade astrocytoma ( $n=12$ cases), which included pilocytic astrocytoma and diffuse astrocytoma.

Preoperative neurological status and postoperative neurological status were re-evaluated using the Nurick score [14] and medical record data on preoperative neurological status: three patients were classified as grade 1 , six patients were classified as grade 2 , four patients were classified as grade 3 , ten patients were classified as grade 4 , and three patients were classified as grade 5 .

\section{Postoperative neurological status}

No patients in our sample were classified as having a Nurick grade of 1; however, four patients were grade 2, five were grade 3 , eight were grade 4 , and nine were grade 5. There was a difference in preoperative neurological status between patients who had a low-grade astrocytoma and those who had a high-grade astrocytoma: $66.7 \%$ of low-grade patients had a neurologic grade of 1,2 , or 3 , while $71.4 \%$ of high-grade patients had a neurological grade of 4 or 5 . There was also a difference in postoperative neurological status between patients who had a lowgrade astrocytoma and those who had a high-grade astrocytoma: $58.3 \%$ of low-grade patients had a neurological grade of 1,2 , or 3 , while $85.7 \%$ of high-grade patients had a neurological grade of 4 or 5 . Overall, we found a significant likelihood of better preoperative $(p=0.006)$ and postoperative neurological status $(p=0.008)$ among lowgrade astrocytoma patients than among high-grade patients.

Duration of the chief complaint prior to diagnosis was also evaluated between low-grade astrocytoma patients and highgrade patients. We found that the duration of low-grade astrocytoma (mean 13.9 months; range 0.25-48 months) was longer than the duration of high-grade astrocytoma (mean 6.4 months; range $0.25-36$ months; $p=0.009$ ).

All of the low-grade astrocytoma patients underwent gross total resection or total resection. Of the 14 high-grade astrocytoma patients, 5 received a subtotal or partial resection ( $p=0.019$; Tables 2,4$)$.

\section{MRI findings}

MRI revealed that 18 patients had a widened spinal cord, a low signal in T1, and a high signal in T2. Four of seven patients with low-grade astrocytoma showed T1 enhancement, and 11 of 11 patients with high-grade astrocytoma showed T1 enhancement with heterogeneous images. Three of seven patients with low-grade astrocytoma and eight of 11 patients with high-grade astrocytoma showed cyst formation. Five of seven patients with low-grade astrocytoma and one of 11 patients with high-grade 
Table 2 Clinical characteristics of 26 patients with spinal-cord astrocytoma

\begin{tabular}{|c|c|c|c|c|c|c|c|c|c|c|c|}
\hline $\begin{array}{l}\text { Patient } \\
\text { no. }\end{array}$ & Age & Sex & $\begin{array}{l}\text { Symptom } \\
\text { duration } \\
\text { (months) }\end{array}$ & $\begin{array}{l}\text { Preop } \\
\text { neurologic } \\
\text { status }\end{array}$ & $\begin{array}{l}\text { Postop } \\
\text { neurologic } \\
\text { status }\end{array}$ & $\begin{array}{l}\text { Histologic } \\
\text { grade }\end{array}$ & $\begin{array}{l}\text { Tumor } \\
\text { location }\end{array}$ & $\begin{array}{l}\text { Surgical } \\
\text { extent }\end{array}$ & Adjuvant Tx & $\begin{array}{l}\text { OS } \\
\text { (months) }\end{array}$ & $\begin{array}{l}\text { PFS } \\
\text { (months) }\end{array}$ \\
\hline 1 & 56 & M & 0.5 & 2 & 3 & III & $\mathrm{T}-\mathrm{L}$ & TR & $\begin{array}{l}\text { RT } \\
\quad(5400 \mathrm{cGy})+\mathrm{CTx}\end{array}$ & 10 & 7 \\
\hline 2 & 75 & $\mathrm{~F}$ & 2 & 3 & 4 & III & $\mathrm{C}$ & STR & RT (6300 cGy) & 5 & 2 \\
\hline 3 & 27 & $\mathrm{~F}$ & 2 & 3 & 4 & III & C-T & STR & $\begin{array}{l}\text { RT } \\
\quad(5400 \text { cGy })+\text { CTx }\end{array}$ & 34 & 12 \\
\hline 4 & 25 & M & 0.5 & 4 & 4 & $\mathrm{II} \rightarrow \mathrm{III}$ & $\mathrm{C}$ & TR & $\begin{array}{l}\text { RT } \\
\quad(5220 \text { cGy })+\text { CTx }\end{array}$ & 22 & 11 \\
\hline 5 & 22 & F & 0.5 & 5 & 5 & IV & $\mathrm{C}$ & STR & RT (4140 cGy) & 8 & 3 \\
\hline 6 & 46 & $\mathrm{~F}$ & 0.25 & 2 & 2 & $\mathrm{II} \rightarrow \mathrm{III}$ & T-L & TR & RT & 12 & 4 \\
\hline 7 & 76 & $\mathrm{~F}$ & 3 & 4 & 5 & IV & $\mathrm{C}$ & STR & & 9 & 9 \\
\hline 8 & 64 & M & 1 & 5 & 5 & IV & $\mathrm{C}$ & STR & RT & 2 & 1 \\
\hline 9 & 19 & $\mathrm{~F}$ & 1 & 4 & 4 & IV & $\mathrm{C}$ & GTR & RT & 2 & 2 \\
\hline 10 & 49 & M & 3 & 4 & 5 & IV & C-T & TR & & 6 & 6 \\
\hline 11 & 52 & M & 3 & 5 & 5 & III & $\mathrm{T}$ & GTR & & 13 & 13 \\
\hline 12 & 39 & M & 36 & 4 & 5 & IV & $\mathrm{T}$ & TR & & 36 & 10 \\
\hline 13 & 50 & M & 36 & 4 & 5 & III & $\mathrm{C}$ & TR & RT (4500 cGy) & 13 & 13 \\
\hline 14 & 41 & M & 1 & 4 & 5 & III & $\mathrm{T}$ & GTR & & 12 & 3 \\
\hline 15 & 23 & M & 8 & 3 & 3 & I & $\mathrm{C}$ & TR & & 28 & 28 \\
\hline 16 & 42 & M & 12 & 1 & 2 & I & $\mathrm{C}$ & $\mathrm{TR}$ & & 43 & 43 \\
\hline 17 & 46 & F & 36 & 1 & 2 & I & $\mathrm{C}$ & TR & & 48 & 48 \\
\hline 18 & 19 & M & 4 & 2 & 4 & I & $\mathrm{T}$ & TR & & 48 & 48 \\
\hline 19 & 29 & M & 12 & 4 & 4 & II & $\mathrm{T}$ & $\mathrm{TR}$ & RT (5000 cGy) & 336 & 336 \\
\hline 20 & 41 & $\mathrm{~F}$ & 9 & 2 & 3 & II & $\mathrm{T}$ & GTR & & 312 & 312 \\
\hline 21 & 57 & $\mathrm{~F}$ & 24 & 2 & 4 & II & $\mathrm{C}$ & GTR & & 240 & 12 \\
\hline 22 & 37 & M & 4 & 4 & 4 & II & $\mathrm{T}$ & GTR & & 42 & 42 \\
\hline 23 & 41 & M & 6 & 2 & 3 & II & $\mathrm{T}$ & GTR & & 480 & 180 \\
\hline 24 & 37 & $\mathrm{M}$ & 48 & 3 & 3 & II & C & GTR & & 84 & 84 \\
\hline 25 & 14 & M & 0.25 & 4 & 5 & II & T-L & $\mathrm{TR}$ & & 72 & 72 \\
\hline 26 & 22 & M & 9 & 1 & 2 & II & T-L & TR & & 36 & 36 \\
\hline
\end{tabular}

astrocytoma had a syrinx formation. T1-enhanced results and syrinx formation were significantly different between patients with low-grade astrocytoma and those with highgrade astrocytoma ( $p=0.021$ and $p=0.041$, respectively; Tables 3, 4).

Heterogeneity and cyst formation were not statistically significant between patients with low-grade astrocytoma and those with high-grade astrocytoma, based on the Mann-Whitney test results (Table 4).

Ki-67 scores for low-grade astrocytoma patients fell within the range of $1-4 \%$ (mean $1.72 \%$ ), while the scores for high-grade astrocytoma patients were within 5-30\% (mean $18.25 \%$ ), which was a statistically significant difference $(p<0.001)$.

The OS of low-grade astrocytoma patients was 28-480 months at the final follow-up (mean
156.38 months), while the OS of high-grade astrocytoma patients was 1-36 months (mean 12.00 months), which was a statistically significant difference $(p<0.001)$.

PFS in low-grade astrocytoma patients was 12-480 months (mean 138.85 months), while PFS in highgrade astrocytoma patients was 1-13 months (mean 6.64 months), which was a statistically significant difference $(p<0.001)$.

Table 5 shows all of the candidate prognostic factors of OS analyzed in the Cox hazards models. The univariate analysis identified tumor grade [hazard ratio (HR) 4.685; $95 \%$ confidential interval (CI) 2.201-9.974; $p<0.001]$ and tumor location (HR 3.002; CI 1.009-8.936; $p=0.048$ ) as being significantly associated with OS. Other factors found to be significantly associated with OS on univariate analysis were preoperative neurological status (HR 2.173; 
Table 3 MRI characteristics of 18 patients with spinal cord astrocytoma

\begin{tabular}{lllllll}
\hline $\begin{array}{l}\text { Case } \\
\text { no. }\end{array}$ & Grade & $\begin{array}{l}\text { Homo/ } \\
\text { hetero }\end{array}$ & T1 & T2 & $\begin{array}{l}\text { T1 } \\
\text { enhance }\end{array}$ & S/C \\
\hline 1 & III & Hetero & Hypo & Hyper & Hyper & \\
2 & III & Hetero & Hypo & Hyper & Hyper & \\
3 & III & Homo & Hypo & Hyper & Hyper & \\
4 & III & Hetero & Hypo & Hyper & Hyper & \\
5 & IV & Hetero & Hypo & Hyper & Hyper & S \\
6 & III & Homo & Hypo & Hyper & Hyper & C \\
7 & IV & Hetero & Hypo & Hyper & Hyper & C \\
10 & IV & Homo & Hypo & Hyper & Hyper & C \\
11 & III & Hetero & Hypo & Hyper & Hyper & C \\
12 & IV & Hetero & Hypo & Hyper & Hyper & \\
13 & III & Hetero & Hypo & Hyper & Hyper & C \\
15 & I & Hetero & Hypo & Hyper & Hype & S \\
16 & I & Hetero & Hypo & Hyper & Hyper & S \\
17 & I & Homo & Hypo & Hyper & Hypo & S \\
18 & I & Homo & Hypo & Hyper & Hyper & S \\
21 & II & Homo & Hypo & Hyper & Hypo & S \\
22 & II & Homo & Hypo & Hyper & Hypo & \\
26 & II & Hetero & Hypo & Hyper & Hyper & C \\
\hline
\end{tabular}

Homo Homogenous, hetero heterogeneous, $T 1$ T1-weighted image, T2 T2-weighted image, Tlc enhanced T1-weighted image, hypo hypointensity, hyper hyperintensity, $S$ syrinx, $C$ cyst

CI 1.241-3.803; $p=0.007)$, postoperative neurological status (HR 2.586; CI 1.314-5.092; $p=0.006$ ), and surgical extent (i.e., total resection/gross total resection vs. subtotal resection/partial resection; HR 5.436; CI 1.517-19.473; $p=0.009$; Figs. 1, 2 and 3). The Ki-67 index score was a significant negative predictor of overall survival (HR 1.078; CI 1.002-1.159; $p=0.045$ ); however, our sample for this variable included only 15 patients. Thus, our statistical power was low, and we thereby excluded the Ki-67 index from multivariate analysis.

Postoperative radiotherapy (RT) was performed in patients with high-grade tumors. We distinguished between low-grade and high-grade astrocytomas based on pathology reports and then analyzed the high-grade group to determine the efficacy of RT, which was not statistically significant (HR 2.855; CI 0.613-13.307; $p=0.182$ ). However, according to Fig. 4, a difference in OS was observed. Overall survival of high-grade patients who had undergone RT was shorter than that of those who had not.

Tumor grade, tumor location, surgical extent, and preoperative and postoperative neurological status were included in the multivariate analysis. Tumor grade (HR 4.353; CI 1.356-13.980; $p=0.013$ ) and location (HR
4.855; CI $1.187-19.851 ; p=0.028)$ were the only variables that remained independently significant (Table 5).

Table 6 shows all of the candidate prognostic factors of PFS analyzed in the Cox hazards model. On univariate analysis, we found that tumor grade (HR 4.091; CI $1.617-10.346 ; p=0.003$ ), surgical extent (HR 5.926; CI $1.621-21.660 ; p=0.007$ ), and Ki-67 index (HR 1.085; CI $1.007-1.170 ; p=0.031$ ) were significantly associated with PFS (Figs. 1, 2 and 3).

RT efficacy was not significant with regard to PFS in the high-grade astrocytoma group (HR 2.130; CI $0.423-10.739 ; p=0.360$ ). However according to the graph, the PFS of patients who had undergone RT was shorter than that of those who had not (Fig. 4).

We performed a multivariate analysis of PFS prognostic factors with tumor grade and surgical extent as our main effect variables. Only tumor grade was independently significant (HR 4.091; CI 1.617-10.346; $p=0.003$; Table 6).

Table 7 shows the characteristics of the two cases of malignant pathologic changes. High-grade astrocytoma was diagnosed in these two patients, who experienced recurrence of diffuse astrocytoma 4 and 11 months after receiving the initial diagnosis; these are referred to as cases 4 and 6 , respectively.

In case 4, open biopsy was performed on March 26, 2013, and no tumor pathology was found. On September 10,2013 , gross total resection was performed, and diffuse astrocytoma was pathologically confirmed. During rehabilitation, neurologic symptoms occurred, and MRI revealed tumor recurrence. On April 9, 2014, gross total resection was also performed, and pathologic high grade astrocytoma was confirmed. Postoperative radiotherapy was performed at $4500 \mathrm{cGy}$, in 25 fractions. Ultimately, a high-grade glioma metastasized to the brain, and despite concurrent chemoradiotherapy, the patient expired. In this case, the undergrading could have been due to the small proportions of the initial biopsy site, which was heterogeneous in nature, suggesting that the diagnosis was not actually due to a malignant transformation but rather to a primarily anaplastic astrocytoma that was undergraded.

In case 6 , her chief complaint was right-leg tightness, and MRI revealed a spinal cord tumor. On October 10, 2014, the tumor was removed via gross total resection, and the pathology was a diffuse astrocytoma that showed mild increased cellularity (Fig. 5a, 100×) with a fibrillary background and moderate cytologic atypia (Fig. 5b, $400 \times)$. The Ki-67 labeling index in this case was approximately $4 \%$ (Fig. 5c, Ki-67, 100×). After 4 months, she experienced a leg sensory change, and MRI showed tumor recurrence. On February 3, 2015, gross total resection of 
Table 4 Demographic data for patients with low-or high-grade astrocytoma

\begin{tabular}{|c|c|c|c|c|}
\hline Factors & Low-grade & High-grade & Total & $p$ value \\
\hline Age & & & $14-76$ (38.9 years) & 0.259 \\
\hline$\leq 40$ & $7(58.3 \%)$ & $5(41.7 \%)$ & 12 & \\
\hline$>40$ & $5(35.7 \%)$ & $9(64.3 \%)$ & 14 & \\
\hline Sex & & & & 0.402 \\
\hline Male & $9(52.9 \%)$ & $8(47.1 \%)$ & 17 & \\
\hline Female & $3(33.3 \%)$ & $6(66.7 \%)$ & 9 & \\
\hline PreopNex & & & & $0.006^{*}$ \\
\hline 1 & 3 & 0 & 3 & \\
\hline 2 & 4 & 2 & 6 & \\
\hline 3 & 2 & 2 & 4 & \\
\hline 4 & 3 & 7 & 10 & \\
\hline 5 & 0 & 3 & 3 & \\
\hline PostopNex & & & & $0.008 *$ \\
\hline 1 & 0 & 0 & 0 & \\
\hline 2 & 3 & 1 & 4 & \\
\hline 3 & 4 & 1 & 5 & \\
\hline 4 & 4 & 4 & 8 & \\
\hline 5 & 1 & 8 & 9 & \\
\hline Duration of $\mathrm{CC}$ & $0.25-48$ (13.9) mo & $0.25-36$ (6.4) months & & $0.009 *$ \\
\hline Location & & & & 0.259 \\
\hline $\mathrm{C}, \mathrm{C}-\mathrm{T}$ & $5(35.7 \%)$ & $9(64.3 \%)$ & 14 & \\
\hline T, T-L & $7(58.3 \%)$ & $5(41.7 \%)$ & 12 & \\
\hline Surgical extent & & & & $0.019 *$ \\
\hline GTR, TR & $12(57.1 \%)$ & $9(42.9 \%)$ & 21 & \\
\hline STR & 0 & $5(100 \%)$ & 5 & \\
\hline Tumor size & $1-4.10(2.48) \mathrm{cc}$ & $1-4.1(2.46) \mathrm{cc}$ & & 0.610 \\
\hline Ki-67 & $1-4(1.72) \%$ & $5-30(18.25) \%$ & & $<0.001$ \\
\hline OS & 28-480 (156.38) months & $1-36$ (12.00) months & & $<0.001$ \\
\hline PFS & 12-480 (138.85) months & $1-13$ (6.64) months & & $<0.001$ \\
\hline MRI findings & 7 & 11 & 18 & \\
\hline T1-enhanced & 4 & 11 & 15 & $0.021 *$ \\
\hline Heterogeneous & 3 & 8 & 11 & 0.218 \\
\hline Cyst & 1 & 5 & 6 & 0.105 \\
\hline Syrinx & 5 & 1 & 6 & $0.041 *$ \\
\hline
\end{tabular}

Asterisk indicates statistical significant data

PreopNex preoperative neurological status, PostopNex postoperative neurological status, OS overall survival, $P F S$ progression-free survival the spinal cord tumor was performed. Contrary to previous diffuse astrocytomas, anaplastic astrocytomas have a moderately increased cellularity (Fig. 5d, 100×) with marked cytologic atypia (Fig. 5e, 400×). Additionally, a marked increase in the Ki-67 labeling index (approximately $20 \%$ ) was noted (Fig. 5f, Ki-67, 100×), suggesting a malignant transformation from diffuse to high-grade astrocytoma. In this case, there was focal enhancement on MR images, and this enhancemet was increased when pathologic high-grade glioma was confirmed (Table 7).

\section{Discussion}

Spinal cord astrocytoma is a rare tumor that has been rarely studied and therefore lacks appropriate treatment guidelines. Malignant spinal cord astrocytomas have particularly poor prognoses $[7,9,15,16]$. Herein, we analyzed behavioral patterns, prognosis factors, and treatment options of spinal cord astrocytoma, and we explored differences in these characteristics according to low-grade or high-grade astrocytoma. 
Table 5 Cox regression analysis of overall survival

\begin{tabular}{|c|c|c|c|c|}
\hline \multirow[t]{2}{*}{ Factor } & \multicolumn{2}{|l|}{ Univariate } & \multicolumn{2}{|l|}{ Multivariate } \\
\hline & HR (95 \% CI) & $p$ value & HR $(95 \%$ CI $)$ & $p$ value \\
\hline Age & $1.192(0.424-3.352)$ & 0.739 & NT & NT \\
\hline Sex & $1.143(0.385-3.393)$ & 0.810 & NT & NT \\
\hline Tumor grade & 4.685 (2.201-9.974) & $<0.001 *$ & $4.353(1.356-13.980)$ & $0.013^{*}$ \\
\hline Tumor location & $3.002(1.009-8.936)$ & $0.048 *$ & $4.855(1.187-19.851)$ & $0.028^{*}$ \\
\hline Tumor size & $1.086(0.896-1.317)$ & 0.400 & NT & NT \\
\hline Ki-67 index & $1.078(1.002-1.159)$ & $0.045^{*}$ & NT & NT \\
\hline PreopNex & $2.173(1.241-3.803)$ & $0.007 *$ & $1.445(0.550-3.794)$ & 0.455 \\
\hline PostopNex & $2.586(1.314-5.092)$ & $0.006^{*}$ & $1.162(0.343-3.942)$ & 0.809 \\
\hline Surgical extent & $5.436(1.517-19.473)$ & $0.009 *$ & $0.935(0.201-4.348)$ & 0.932 \\
\hline Postop RT & $2.855(0.613-13.307)$ & 0.182 & NT & NT \\
\hline
\end{tabular}

Asterisk indicates statistical significant data

$C I$ Confidence interval, $H R$ hazard ratio, PreopNex preoperative neurological status, Postop ex postoperative neurological status, Postop RT postoperative radiotherapy, $N T$ not tested

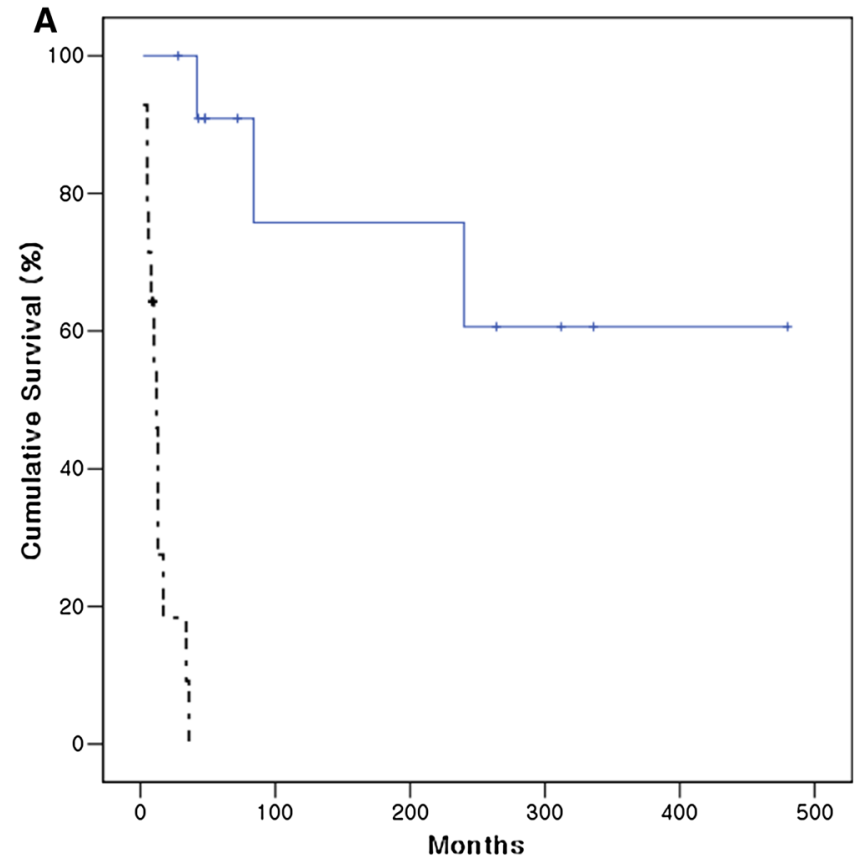

Fig. 1 Tumor grade and overall survival/progression-free survival. a Overall survival of low-grade and high-grade astrocytoma patients. Continuous line low-grade astrocytoma, dotted line high-grade astrocytoma. log-rank test $p$ value $<0.001$. b Progression-free survival

Typically, high-grade astrocytomas involve a shorter symptom duration prior to diagnosis than low-grade astrocytomas, and there is also a statistically significant difference in neurological status before and after surgery. We found a statistically significant difference in the surgical extent between low-grade and high-grade cases: total or gross total resection was common in low-grade cases, while subtotal or partial resection only occurred among high-grade cases. This was likely due to the fact that high-

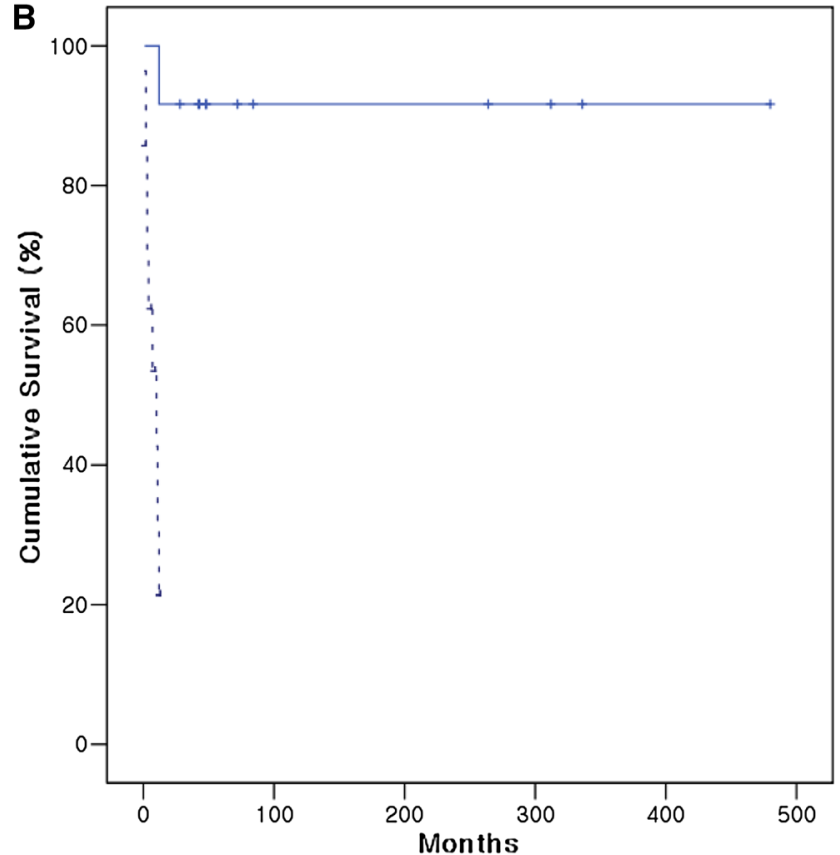

of low-grade and high-grade astrocytoma patients. Continuous line low-grade astrocytoma, dotted line high-grade astrocytoma. log-rank test $p$ value $<0.001$

grade astrocytomas grow in a more rapid and invasive manner than low-grade astrocytomas and are therefore more challenging to resect.

In previous studies, histologic grade was emphasized as a significant prognostic factor $[6,8,16-18]$. In our study, histologic grade and tumor location were significant prognostic factors of $\mathrm{OS}$ in both univariate and multivariate analyses. Preoperative and postoperative neurological status and surgical extent were also 


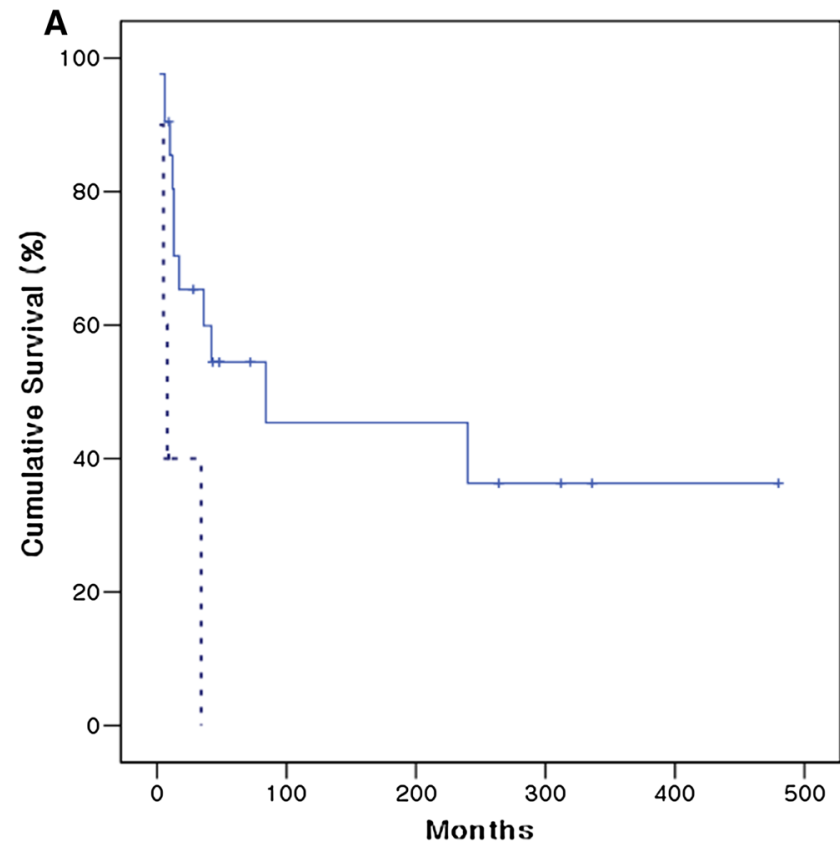

Fig. 2 Surgical extent and overall and progression-free survival. a Overall survival of patients who received total resection or gross total resection vs. subtotal resection or partial resection. Continuous line (gross) total resection, dotted line subtotal/partial resection. log-

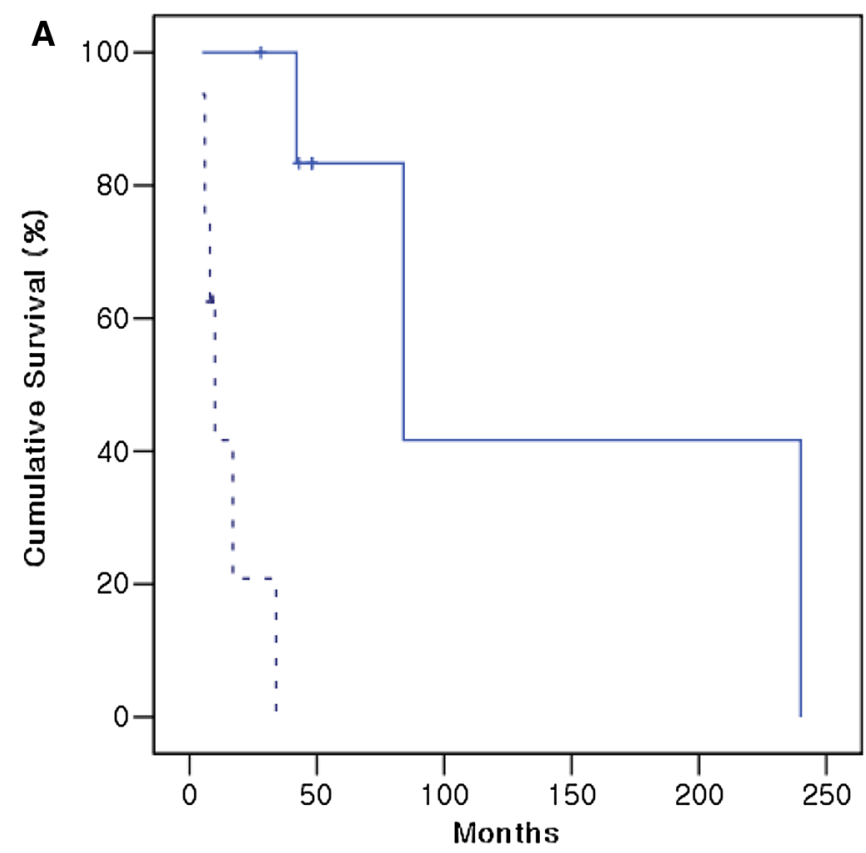

Fig. $3 \mathrm{Ki}-67$ index and overall and progression-free survival. a Overall survival according to $\mathrm{Ki}-67$ index. Continuous line $\mathrm{Ki}$ index $<5 \%$, dotted line $\mathrm{Ki}$ index $\geq 5 \%$. log-rank test $p$ value $<0.001$.

statistically significant on univariate analysis yet not on multivariate analysis. Histologic grade and surgical extent were significant prognostic factors of PFS on

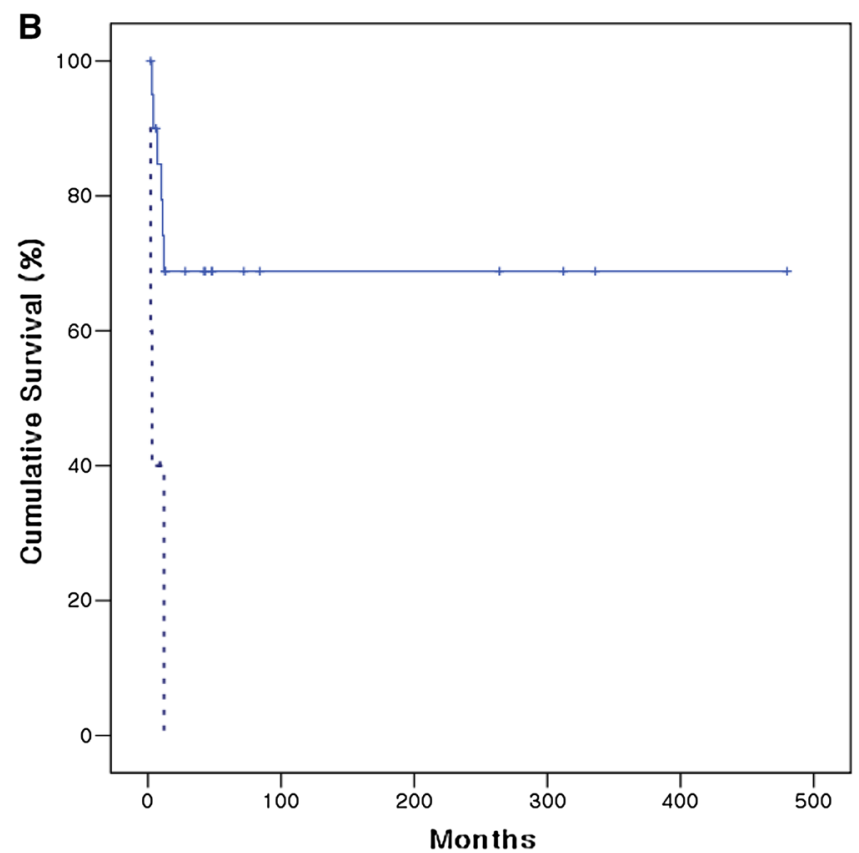

rank test $p$ value $=0.004$. $\mathbf{b}$ Progression-free survival of patients who received total resection or gross total resection vs. subtotal resection or partial resection. Continuous line (gross) total resection, dotted line subtotal/partial resection. log-rank test $p$ value $=0.002$

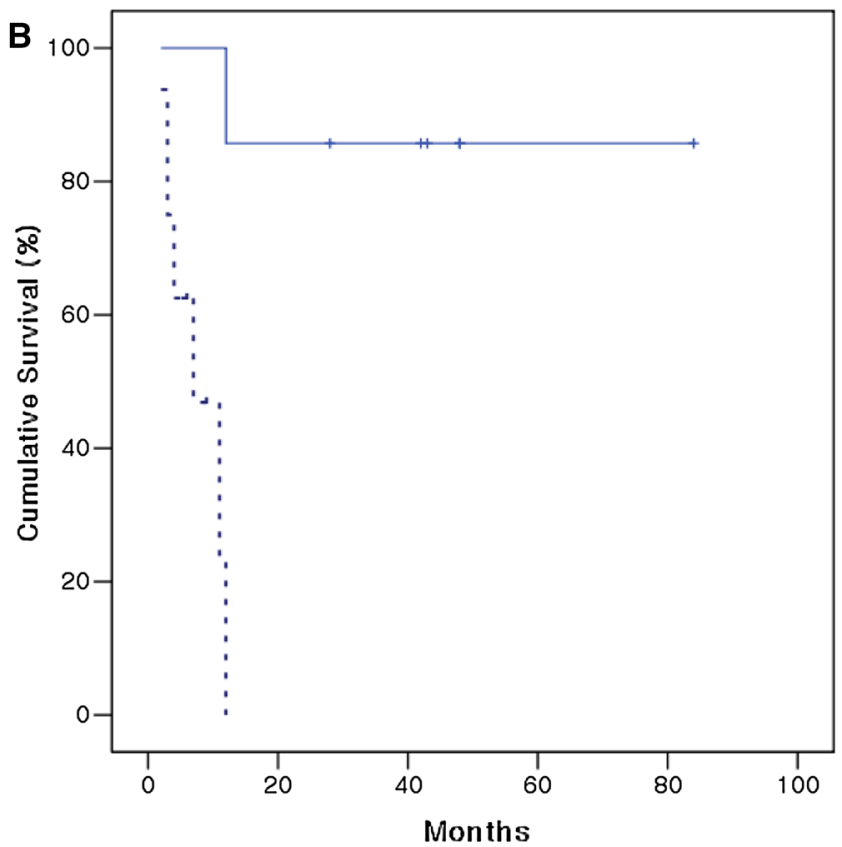

b Progression-free survival according to Ki-67 index. Continuous line $\mathrm{Ki}$ index $<5 \%$, dotted line $\mathrm{Ki}$ index $\geq 5 \%$. log-rank test $p$ value $=0.002$

univariate analysis, while only histologic grade was a significant independent predictor of PFS on multivariate analysis. 


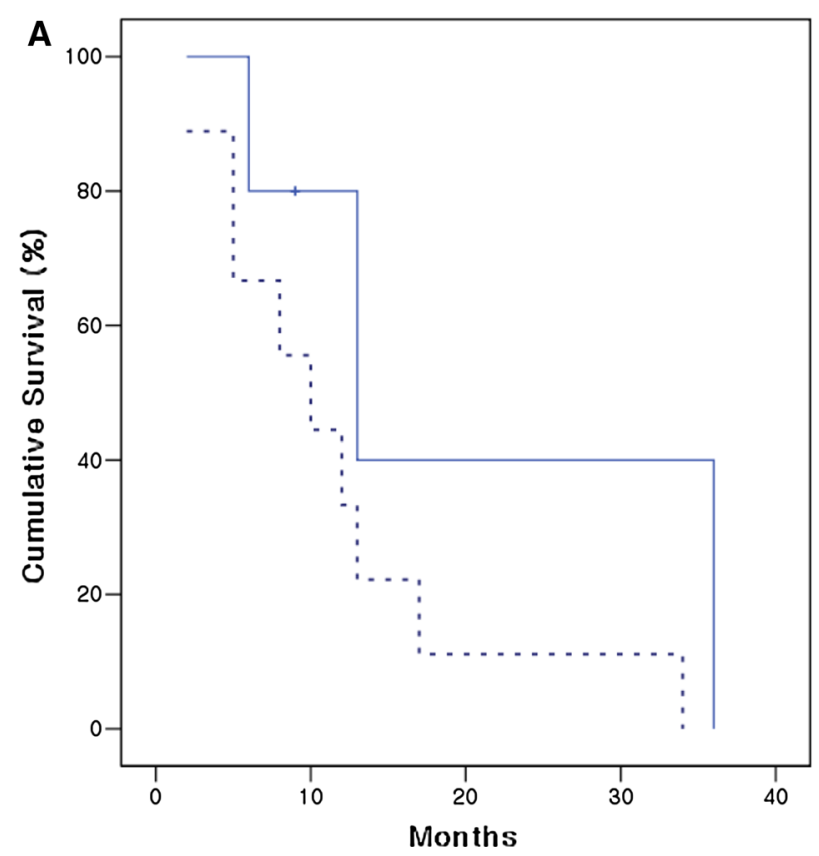

Fig. 4 Postoperative radiotherapy and overall and progression-free survival in high-grade astrocytoma patients. a Overall survival of high-grade astrocytoma patients who did not undergo postoperative radiotherapy (solid line) was compared to patients who received postoperative radiotherapy (dashed line), and the difference was not

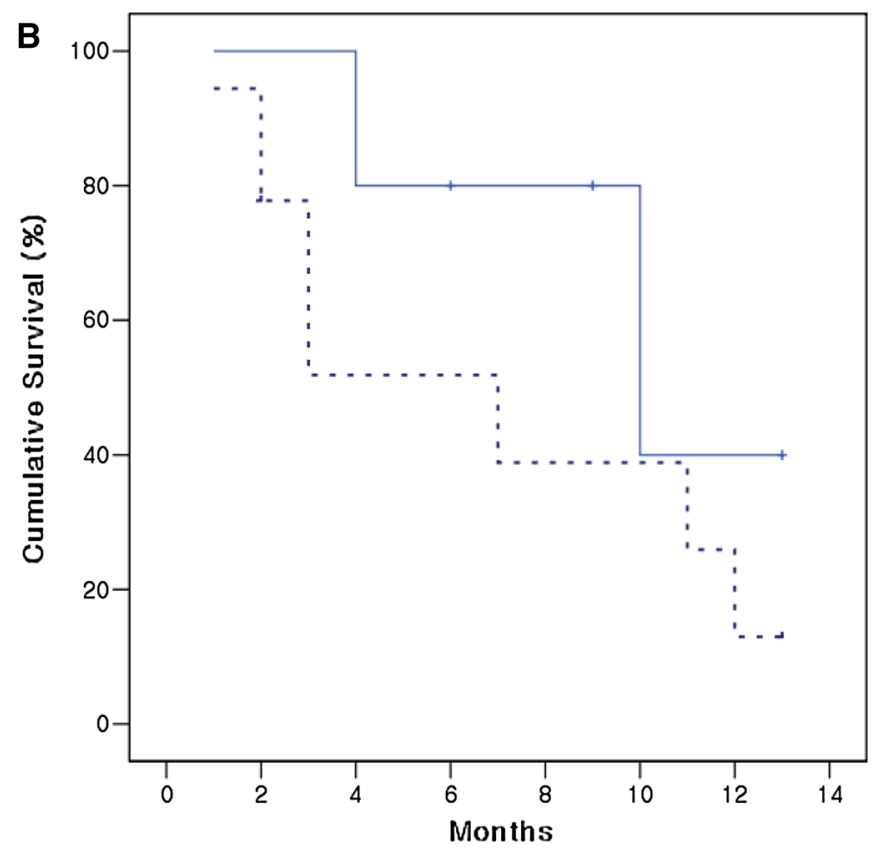

significant (log-rank test $p$ value $=0.15)$. b Progression-free survival of high-grade astrocytoma patients who did not undergo postoperative radiotherapy (solid line) was compared to patients who received postoperative radiotherapy (dashed line), and the difference was not significant (log-rank test $p$ value 0.26 )
Table 6 Cox regression analysis of progression-free survival

\begin{tabular}{|c|c|c|c|c|}
\hline \multirow[t]{2}{*}{ Factor } & \multicolumn{2}{|l|}{ Univariate } & \multicolumn{2}{|l|}{ Multivariate } \\
\hline & HR $(95 \%$ CI $)$ & $p$ value & HR $(95 \%$ CI $)$ & $p$ value \\
\hline Age & $1.577(0.443-5.612)$ & 0.482 & NT & NT \\
\hline Sex & $2.488(0.716-8.639)$ & 0.151 & NT & NT \\
\hline Tumor grade & $4.091(1.617-10.346)$ & $0.003 *$ & $3.473(1.278-9.440)$ & $0.015 *$ \\
\hline Tumor location & $1.582(0.446-5.615)$ & 0.478 & NT & NT \\
\hline Tumor size & $0.964(0.699-1.328)$ & 0.821 & NT & NT \\
\hline Ki-67 index & $1.085(1.007-1.170)$ & $0.031 *$ & NT & NT \\
\hline PreopNex & $1.396(0.810-2.407)$ & 0.230 & NT & NT \\
\hline PostopNex & $1.559(0.798-3.045)$ & 0.193 & NT & NT \\
\hline Surgical extent & $5.926(1.621-21.660)$ & $0.007 *$ & $2.041(0.499-8.344)$ & 0.321 \\
\hline Postop RT & $2.130(0.423-10.739)$ & 0.360 & NT & NT \\
\hline
\end{tabular}

Asterisk indicates statistical significant data

CI Confidence interval, HR hazard ratio, PreopNex preoperative neurological status, PostopNex postoperative neurological status, Postop RT postoperative radiotherapy, $N T$ not tested
Eighteen of the 26 patients in our study had MRI data that we could review. Many of the high-grade astrocytomas were enhanced and heterogeneous, while the lowgrade astrocytomas were generally unenhanced and homogenous on enhanced T1-weighted imaging. Spinal cord enlargement usually occurs in response to an astrocytoma, and this can be observed on MRI, based on homogenous or heterogeneous signal patterns along with hypo- or iso-signal intensity on T1-weighted images or hyper-signal intensity on T2-weighted images. We found statistical differences in syrinx formation and $\mathrm{T} 1$ enhancement between low-grade and high-grade cases. Cysts usually accompanied a high-grade astrocytoma. Syrinxes, which form after a change in CSF flow [19, 20], were observed in one of 11 high-grade cases and in five of seven low-grade cases. This could be due to the fact that low-grade tumors have fewer infiltrates than highgrade tumors, resulting in a greater impact on CSF flow in 
Table 7 Two cases of malignant pathologic changes

\begin{tabular}{|c|c|c|}
\hline & Case. 4 & Case. 6 \\
\hline Age & 25 & 46 \\
\hline Sex & Male & Female \\
\hline Tumor location & From cervical 2 to thoracic 2 & From thoracic 12 to lumbar 1 \\
\hline \multirow[t]{3}{*}{ Surgical extent } & Open biopsy (2013.03.26) & Gross total resection $(2014.10 .10)^{\mathrm{a}}$ \\
\hline & Gross total resection $(2013.09 .10)^{\mathrm{a}}$ & Gross total resection $(2015.02 .03)^{\mathrm{b}}$ \\
\hline & Gross total resection $(2014.04 .09)^{\mathrm{b}}$ & \\
\hline Tumor grade & WHO grade II $\rightarrow$ III & WHO grade II $\rightarrow$ III \\
\hline Ki-67 index & $3 \rightarrow 30 \%$ & $4 \rightarrow 20 \%$ \\
\hline MRI enhancement & None $\rightarrow$ enhance & Focal enhance $\rightarrow$ increased enhance \\
\hline OS (months) & 22 & 12 \\
\hline PFS (months) & 11 & 4 \\
\hline Postop RT ${ }^{\mathrm{c}}$ & $4500 \mathrm{cGy}, 25$ fraction & $4140 \mathrm{cGy}, 23$ fraction \\
\hline Metastasis & Brain metastasis & None \\
\hline $\mathrm{CCRT}^{\mathrm{d}}$ & $\begin{array}{l}\text { Temodal + IMRT (brain: } 3750 \text { cGy, } 15 \text { fraction, } \\
\text { Spine } 3000 \text { cGy, } 12 \text { fraction) }\end{array}$ & None \\
\hline
\end{tabular}

\footnotetext{
${ }^{a}$ The time of pathologic low grade confirmation

b The time of pathologic low-grade confirmation

c Postoperative radiotherapy after pathologic high-grade confirmation

${ }^{\mathrm{d}}$ Concurrent chemoradiotherapy after brain metastasis
}
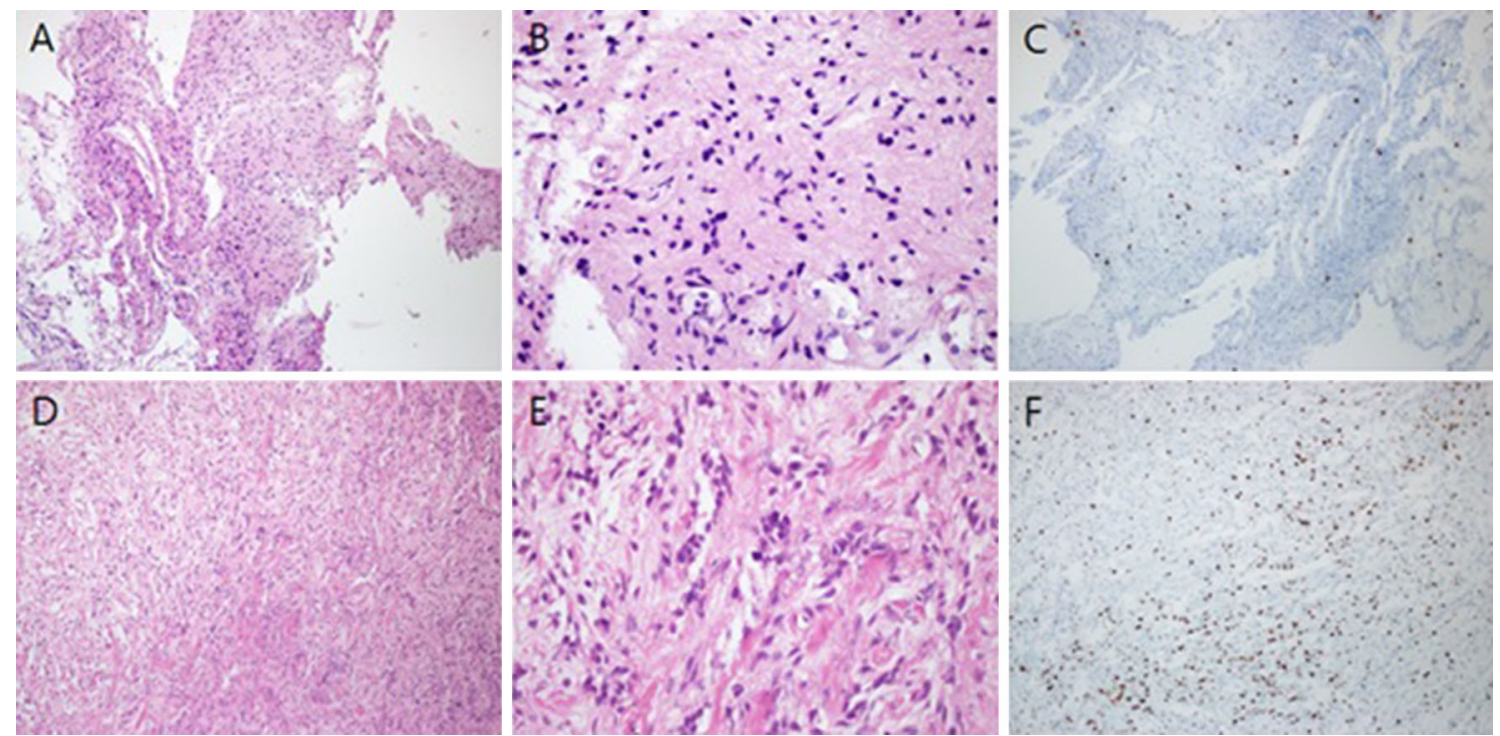

Fig. 5 Pathology comparison between diffuse astrocytoma and anaplastic astrocytoma. Diffuse astrocytoma: a $100 \times$, b $400 \times$, c Ki-67, 100× (Ki-67 labeling). Anaplastic astrocytoma: d 100×, e 400×, f Ki-67, 100× (Ki-67 labeling)

the spinal cord. More research on the effect of tumor grade on syrinxes is needed.

All surgeries were performed by two experienced neurosurgeons at a single institution, and all preoperative and postoperative assessments were conducted using the same analytic tools. Adams et al. reported that radical resection was associated with extended survival for patients with AA yet not those with GB [21]. McGirt et al. observed that radical resection of $\mathrm{AA}$ was associated with a trend of increased overall survival in nondisseminated AA cases. Radical surgery and radiotherapy of GBM was associated with poor survival [15]. Babu et al. showed that surgical intervention is associated with a higher rate of neurological complications [22], and Raco et al. also observed a 
worsening of the neurological deficit associated with the extent of resections, noting that total surgical removal of high-grade spinal cord lesions was rarely practicable [23]. Fakhreddine et al. and Innocenzia et al. the extent of resection did not influence survival benefits within each histological grade $[6,17]$. Given that low-grade astrocytomas were more likely to be grossly or totally resected than high-grade astrocytomas, which were more likely to be partially resected, surgical extent alone is too simplistic as a prognostic factor. Consequently, we analyzed highgrade astrocytomas alone using a Cox hazards analysis in order to determine the relationships between surgical extent and OS (HR 1.443; CI 0.408-5.105; $p=0.569)$ and PFS (HR 2.098; CI 0.558-7.886; $p=0.273$ ). In our study, similar to those by Fakhreddine et al. and Innocenzia et al. $[6,17]$, the extent of resection in high-grade spinal cord glioma was not found to have a statistically significant correlation with OS or PFS.

Eicker et al. suggested that the use of 5-ALA fluorescence could be beneficial, especially in intramedullary gliomas [24]. Our surgeon also considered that the use of 5-ALA flourescence in intramedullary gliomas could be helpful for surgical outcomes, likewise at the brain glioma surgery area. However, there are restrictions on the use of drugs that are not approved by the Korea Institute for Health and Welfare in the Korea National Health Insurance. In the future, the authors will proceed with spinal cord tumor removal after using 5-ALA that has been approved for research purposes.

Postoperative radiotherapy mainly targeted high-grade astrocytoma cases, which significantly impacted survival, although this result was highly likely to be selectively biased. In a previous study, Merachnt et al. reported a survival benefit from radiotherapy in a pediatric population of high-grade spinal cord tumors [25], and Shirato et al. suggested that postoperative conventional radiotherapy is indicated after less than total resection of low-grade astrocytomas and that radiocordectomy may be an option for certain cases with high-grade astrocytic tumors [26]. However, Santi et al., Fakhreddine et al. and Adams et al. did not observe any benefits of radiotherapy [1, 17, 21]. In our study, OS and PFS in the high-grade group that received RT appeared lower on the graph. Moreover, RT, when used in conventional fractionation, can cause radiation injury to the spinal cord [27, 28]. However, RT was more often administered to patients who underwent subtotal or partial resection depending on the postoperative state, which was the reason for the potential selection bias in our study.

Interpretations and reviews of pathology reports were conducted by an experienced neuropathologist who had conducted pathologic gene alteration of high-grade spinal cord analyses for previous studies [29]. In case 4, we performed the immunohistochemical stain. P53 was diffuse strong positive, EGFR was positive $(2+)$, and Ki-67 was $30 \%$ in tumor cells. Similar to a previous study in which malignant spinal cord astrocytoma usually disseminated following neuraxis [9] and a recent study on low-grade astrocytoma leptomeningeal dissemination to the brain [30], our case also had EGFR positivity and neuraxis dissemination with malignant transformation. Promoter methylation of the MGMT gene and $I D H 1$ mutation were not observed. Oligodendroglioma analysis indicated that $1 \mathrm{p}$ $\mathrm{LOH}$ was positive and $19 \mathrm{q} \mathrm{LOH}$ was negative. These results show that malignant transformation of spinal cord astrocytoma may involve different genetic alterations of cranial astrocytoma.

The Ki-67 value as a progression marker has long been thought to be a powerful morphologic predictor of the biological behavior of glial neoplasms [31, 32]. Fifteen of 26 of our study patients had available Ki-67 values, which were statistically significant as a prognostic factor.

A prior report found survival benefits of temozolomide after radiotherapy in six patients with malignant primary spinal cord tumors [10]. Fakhreddine et al. also reported that among patients with infiltrative astrocytomas, chemotherapy was significantly associated with improved PFS yet not OS on multivariate analysis [17]. However, in our study, only three patients who were diagnosed with high-grade astrocytoma went through adjuvant chemotherapy, which yielded no significant survival benefits during follow-up. On June 2, 2009, Case 1 received 5400 cGy of adjuvant radiotherapy with vincristine and carboplatin after total resection. We then changed the chemoregimen to temozolomide after detecting tumor progression on July 18, 2009. Case 1 was discharged on November 5, 2009 due to continued tumor progression. Case 2 underwent $6300 \mathrm{cGy}$ of postoperative radiotherapy following subtotal resection and was administered temozolomide as an adjuvant chemotherapy. However, tumor progression was detected 2 months later, and the patient died 5 months after the initial diagnosis. Case 4 underwent two biopsies after the detection of a spinal cord tumor and was diagnosed with diffuse astrocytoma, for which the patient underwent total resection. Next, the patient underwent $5400 \mathrm{cGy}$ of RT, followed by one cycle of temodal. The patient is currently in OPD follow-up and has had an anaplastic astrocytoma for 11 months. The remaining patients did not receive chemotherapy and were thus excluded from this analysis.

There were several limitations in our study. Due to the rarity of spinal cord glioma, we had no choice but to perform a retrospective observational case series study at a single institution. Additionally, there was a great deal of heterogeneity in regards to the treatment of each patient, even within each subgroup. As we have had no treatment guidelines for spinal cord astrocytoma in the past decade, this heterogeneity was inevitable in this retrospective 
study. In the future, with evidence-based proper guidelines, a well-controlled prospective study will be performed. If the periphery of the mass had been biopsied, the limited amount of tissue that was commonly available for pathology may have led to a lower-grade tumor diagnosis. Case 4 should be considered in light of the potential for sampling error. As spinal cord tumor pathology was examined in a small portion of tumor, pathologic confirmation of lowgrade glioma always revealed all fields of the tumor. Considering sampling error and our experience of pathologic changes, we should consider a treatment plan that correlates with MRI findings. Given that MRI enhancement is correlated with malignant features, despite the pathology of low-grade glioma, we suggest a more aggressive strategy for postoperative treatment.

\section{Conclusion}

Pathologic grade is the strongest prognostic factor of OS and PFS in spinal cord astrocytoma; however, it is not always concordant with biologic behaviors. We observed two cases of so-called malignant transformation at 4 and 11 months, respectively. For this reason, we suggest close observation and image correlation of low-grade astrocytoma despite pathologic confirmation. Postoperative adjuvant therapies, including radiotherapy and chemotherapy, have not been well studied for astrocytoma, and more research on genetic fields is needed.

\section{Compliance with ethical standards}

Conflict of interest None of the authors has any potential conflict of interest.

Open Access This article is distributed under the terms of the Creative Commons Attribution 4.0 International License (http://crea tivecommons.org/licenses/by/4.0/), which permits unrestricted use, distribution, and reproduction in any medium, provided you give appropriate credit to the original author(s) and the source, provide a link to the Creative Commons license, and indicate if changes were made.

\section{References}

1. Santi M, Mena H, Wong K, Koeller K, Olsen C, Rushing EJ (2003) Spinal cord malignant astrocytomas. Clinicopathologic features in 36 cases. Cancer 98:554-561. doi:10.1002/cncr.11514

2. Reimer R, Onofrio BM (1985) Astrocytomas of the spinal cord in children and adolescents. J Neurosurg 63:669-675. doi:10.3171/ jns. 1985.63.5.0669

3. Sandler HM, Papadopoulos SM, Thornton AF Jr, Ross DA (1992) Spinal cord astrocytomas: results of therapy. Neurosurgery 30:490-493

4. Louis DN, Ohgaki H, Wiestler OD, Cavenee WK, Burger PC, Jouvet A, Scheithauer BW, Kleihues P (2007) The 2007 WHO classification of tumours of the central nervous system. Acta Neuropathol 114:97-109. doi:10.1007/s00401-007-0243-4

5. Epstein FJ, Farmer JP, Freed D (1992) Adult intramedullary astrocytomas of the spinal cord. J Neurosurg 77:355-359. doi:10. 3171/jns.1992.77.3.0355

6. Innocenzi G, Salvati M, Cervoni L, Delfini R, Cantore G (1997) Prognostic factors in intramedullary astrocytomas. Clin Neurol Neurosurg 99:1-5

7. Minehan KJ, Shaw EG, Scheithauer BW, Davis DL, Onofrio BM (1995) Spinal cord astrocytoma: pathological and treatment considerations. J Neurosurg 83:590-595. doi:10.3171/jns.1995. 83.4.0590

8. Kim MS, Chung CK, Choe G, Kim IH, Kim HJ (2001) Intramedullary spinal cord astrocytoma in adults: postoperative outcome. J Neurooncol 52:85-94

9. Cohen AR, Wisoff JH, Allen JC, Epstein F (1989) Malignant astrocytomas of the spinal cord. J Neurosurg 70:50-54. doi:10. 3171/jns.1989.70.1.0050

10. Kim WH, Yoon SH, Kim CY, Kim KJ, Lee MM, Choe G, Kim IA, Kim JH, Kim YJ, Kim HJ (2011) Temozolomide for malignant primary spinal cord glioma: an experience of six cases and a literature review. J Neurooncol 101:247-254. doi:10.1007/ s11060-010-0249-y

11. Houten JK, Cooper PR (2000) Spinal cord astrocytomas: presentation, management and outcome. J Neurooncol 47:219-224

12. Miller DC (2000) Surgical pathology of intramedullary spinal cord neoplasms. J Neurooncol 47:189-194

13. Sun B, Wang C, Wang J, Liu A (2003) MRI features of intramedullary spinal cord ependymomas. J Neuroimag Off J Am Soc Neuroimag 13:346-351

14. Nurick S (1972) The natural history and the results of surgical treatment of the spinal cord disorder associated with cervical spondylosis. Brain J Neurol 95:101-108

15. McGirt MJ, Goldstein IM, Chaichana KL, Tobias ME, Kothbauer KF, Jallo GI (2008) Extent of surgical resection of malignant astrocytomas of the spinal cord: outcome analysis of 35 patients. Neurosurgery 63:55-61

16. Roonprapunt C, Houten JK (2006) Spinal cord astrocytomas: presentation, management, and outcome. Neurosurg Clin N Am 17:29-36. doi:10.1016/j.nec.2005.10.006

17. Fakhreddine MH, Mahajan A, Penas-Prado M, Weinberg J, McCutcheon IE, Puduvalli V, Brown PD (2013) Treatment, prognostic factors, and outcomes in spinal cord astrocytomas. Neuro-Oncol 15:406-412. doi:10.1093/neuonc/nos309

18. Kopelson G, Linggood RM (1982) Intramedullary spinal cord astrocytoma versus glioblastoma. The prognostic importance of histologic grade. Cancer 50:732-735

19. Heiss JD, Snyder K, Peterson MM, Patronas NJ, Butman JA, Smith RK, Devroom HL, Sansur CA, Eskioglu E, Kammerer WA, Oldfield EH (2012) Pathophysiology of primary spinal syringomyelia. J Neurosurg Spine 17:367-380. doi:10.3171/ 2012.8.SPINE111059

20. Heiss JD, Suffredini G, Smith R, DeVroom HL, Patronas NJ, Butman JA, Thomas F, Oldfield EH (2010) Pathophysiology of persistent syringomyelia after decompressive craniocervical surgery: Clinical article. J Neurosurg Spine 13:729-742. doi:10. 3171/2010.6.SPINE10200

21. Adams H, Avendano J, Raza SM, Gokaslan ZL, Jallo GI, Quinones-Hinojosa A (2012) Prognostic factors and survival in primary malignant astrocytomas of the spinal cord: a populationbased analysis from 1973 to 2007. Spine 37:E727-E735. doi:10. 1097/BRS.0b013e31824584c0

22. Babu R, Karikari IO, Owens TR, Bagley CA (2014) Spinal cord astrocytomas a modern 20-year experience at a single institution. Spine 39:533-540. doi:10.1097/Brs.0000000000000190 
23. Raco A, Piccirilli M, Landi A, Lenzi J, Delfini R, Cantore G (2010) High-grade intramedullary astrocytomas: 30 years' experience at the Neurosurgery Department of the University of Rome "Sapienza". J Neurosurg Spine 12:144-153. doi:10.3171/2009.6. SPINE08910

24. Eicker SO, Floeth FW, Kamp M, Steiger HJ, Hanggi D (2013) The impact of fluorescence guidance on spinal intradural tumour surgery. Eur Spine J 22:1394-1401. doi:10.1007/s00586-013-2657-0

25. Merchant TE, Nguyen D, Thompson SJ, Reardon DA, Kun LE, Sanford RA (1999) High-grade pediatric spinal cord tumors. Pediatr Neurosurg 30:1-5. doi:10.1159/000028751

26. Shirato H, Kamada T, Hida K, Koyanagi I, Iwasaki Y, Miyasaka $\mathrm{K}$, Abe $\mathrm{H}$ (1995) The role of radiotherapy in the management of spinal cord glioma. Int J Radiat Oncol Biol Phys 33:323-328

27. Linstadt DE, Wara WM, Leibel SA, Gutin PH, Wilson CB, Sheline GE (1989) Postoperative radiotherapy of primary spinal cord tumors. Int J Radiat Oncol Biol Phys 16:1397-1403

28. Garcia DM (1985) Primary spinal cord tumors treated with surgery and postoperative irradiation. Int J Radiat Oncol Biol Phys 11:1933-1939
29. Heo DH, Kim SH, Yang K-M, Cho YJ, Kim KN, Kang T-C (2012) A histopathological diagnostic marker for human spinal astrocytoma: expression of glial fibrillary acidic protein- $\delta$. J Neurooncol 108:45-52

30. Abel TJ, Chowdhary A, Thapa M, Rutledge JC, Geyer JR, Ojemann J, Avellino AM (2006) Spinal cord pilocytic astrocytoma with leptomeningeal dissemination to the brain: case report and review of the literature. J Neurosurg Pediatr 105:508-514

31. Kirla R, Salminen E, Huhtala S, Nuutinen J, Talve L, Haapasalo $\mathrm{H}$, Kalimo H (2000) Prognostic value of the expression of tumor suppressor genes p53, p21, p16 and prb, and Ki-67 labelling in high grade astrocytomas treated with radiotherapy. J Neurooncol 46:71-80

32. Montine TJ, Vandersteenhoven JJ, Aguzzi A, Boyko OB, Dodge RK, Kerns BJ, Burger PC (1994) Prognostic-significance of Ki67 proliferation index in supratentorial fibrillary astrocytic neoplasms. Neurosurgery 34:674-678 